\title{
Degradation of Power Contacts in Industrial Atmosphere: Silver Corrosion and Whiskers
}

\author{
Bella H. Chudnovsky \\ Square D Company \\ West Chester, OH 45069, USA
}

\begin{abstract}
Degradation of power contacts in corrosive atmosphere leads to significant increase of the contact resistance and consequently to a rise in temperature, and eventually to the failure. In electrical apparatus, both base metal copper and silver plating heavily corrode in environment containing sulfuric gases. In addition, expansive growth of silver filaments (whiskers) has been often found on primary current conductors of circuit breakers. This paper describes extensive whisker growth found in switchgear at paper recycling mill. The major environmental factor to initiate the growth is relatively low concentration of Hydrogen Sulfide $\left(\mathrm{H}_{2} \mathrm{~S}\right)$. As soon as a thick enough layer of silver sulfide has been formed, metal filaments start to grow virtually everywhere but most intensely in locations usually having elevated temperature while electrical units are energized. Though hazardous phenomenon has been seen from 1920s and caused a number of violent failures, but it was practically neither studied nor understood. Just in two months after previous cleaning, we found the filaments up to several inches $(6-8 \mathrm{~cm})$ long and up to 0.04 in $(1 \mathrm{~mm})$ thick. Using SEM/EDS analysis we have determined chemical composition and morphology of the whiskers. Most of the whiskers are made of silver with 1-3 \% of copper. The surface of the whiskers long exposed to atmosphere is contaminated with silver sulfide. After thoroughly investigating the factors that initiate and accelerate whiskers' growth we have determined effective means eliminating extremely hazardous phenomenon
\end{abstract}

\section{For more information, contact:}

Bella H. Chudnovsky

Staff Engineer

Schneider Electric North America/Square D

9870 Crescent Park Drive

West Chester, OH 45069

chudnovb@squared.com

Copyright (C) 2002 IEEE. Reprinted from Proceedings of the Forty-Eighth IEEE Holm Conference on Electrical Contacts, 2002, p. 140-150.

This material is posted here with permission of the IEEE. Such permission of the IEEE does not in any way imply IEEE endorsement of any of NASA's products or services. Internal or personal use of this material is permitted. However, permission to reprint/republish this material for advertising or promotional purposes or for creating new collective works for resale or redistribution must be obtained from the IEEE by writing to pubs-permissions@ieee.org.

By choosing to view this document, you agree to all provisions of the copyright laws protecting it. 


\section{INTRODUCTION}

Sulfur rich environments are common at industrial facilities such as petroleum and chemical plants, refineries, paper and pulp recycling plants, sewer and wastewater plants. Such atmosphere produced by various chemical technologies causes a serious corrosion problem for many metals used in electrical apparatus.

This paper is presenting a corrosion effect of such atmospheres on silver, which is very sensitive to the presence of Hydrogen Sulfide $\left(\mathrm{H}_{2} \mathrm{~S}\right)$ even at very low concentration of this highly corrosive gas.

Silver plating is widely used on contacts and other conductive parts in electrical apparatus such as switchgear and motor control centers because of the superior conductivity and longevity. The silver is found on the bus, in the circuit breaker, in protective relays, auxiliary relays, control switches, and test switches. The decomposition of the contact surfaces leads to an increase of the contact resistance and consequently to a rise in temperature, and eventually to the failure.

The paper analyzes the major factors initiating and accelerating the growth of the whiskers on silver plating in electrical apparatus.

\section{CORROSION OF SILVER IN SULFUR RICH ENVIRONMENT}

Silver sulfide is the major product of silver corrosion in atmosphere containing sulfuric gases, such as $\mathrm{H}_{2} \mathrm{~S}$, OCS, $\mathrm{CS}_{2}$, and $\mathrm{SO}_{2}$. Corrosive effect on silver of $\mathrm{H}_{2} \mathrm{~S}$ and OCS gases is about an order of magnitude stronger than that of $\mathrm{CS}_{2}$ and $\mathrm{SO}_{2}$. However, silver sulfide can be formed by contact with $\mathrm{SO}_{2}$ in moist air, but only at $\mathrm{SO}_{2}$ concentration two to three orders of magnitude higher than typical of ambient environments.

Hydrogen Sulfide $\left(\mathrm{H}_{2} \mathrm{~S}\right)$ is usually present at the chemical plants, oil refineries, production of artificial fibers, steel mills, and the paper and pulp processing industry due to process technologies. It was found that even at minor concentration of $\mathrm{H}_{2} \mathrm{~S}$ in atmosphere, corrosion produces silver sulfide on the parts being in contact with environment $[1,2]$.

In electrical apparatus, conductive parts are usually made of Copper with Silver plating. Both base metal $(\mathrm{Cu})$ and plating $(\mathrm{Ag})$ corrode in this environment. Two processes are active at the same time: general corrosion of silver and creep corrosion of copper.

In recent years, investigations on silver plated contacts used in such industrial environment, have in some cases shown also strong indication of growth of copper corrosion products on silver plated surfaces. Unlike most other corrosion films, the growth of the silver sulfide film is linear over time [3]. There are many factors such as other pollutants, exposure time, thickness of silver coating and its porosity, which strongly effect silver corrosion. 
When there is a thick enough layer of $\mathrm{Ag}_{2} \mathrm{~S}$ and a high enough temperature, the new process of growing thin filaments (whiskers) begins. Silver whiskers usually grow in certain areas of the switchgear where they are exposed to $\mathrm{H}_{2} \mathrm{~S}$. They grow practically everywhere but more intensely in the areas with higher temperature, such as bus joints and sliding contacts, outside edges and corners of the contacts. Temperature gradients in these areas may encourage this phenomenon.

Silver corrosion results in a high resistance, which produces more heat, which in turn stimulates the further tarnishing and the growth of the whiskers. This process continues and leads to the failure due to overheating or short circuit, unless timely maintenance prevents the whiskers from getting long enough to reach a ground plane or adjacent pole.

In general the phenomenon of growing thin metal filaments from electrodeposited metals is widely described in technical and scientific literature. As is shown in the following section this growth is not a corrosion phenomenon.

\section{NON-CORROSIVE GROWTH OF WHISKERS}

Thin metal whiskers growing from electroplated tin were first reported found on electronic hardware in 1946. Since then whisker phenomenon was investigated, thoroughly analyzed and reported in dozens of papers [see some of them, 4-8]. Such metals as Zinc (Zn) and Cadmium (Cd) [9], as well as Aluminum (Al), Tungsten (W), Copper, $(\mathrm{Cu})$, Silver $(\mathrm{Ag})$ and Gold $(\mathrm{Au})$, and others also grow thin needle-like filaments under different conditions.

The following data describe some of the generally accepted characteristics of tin whiskers and their formation. They are the same for other metal whiskers: $\mathrm{Zn}, \mathrm{Cd}, \mathrm{Al}$, etc. Whiskers are elongated single crystals of pure metal that have been reported to grow to more than $4 \mathrm{~mm}$ in length with diameter from 0.3 to $10 \mu \mathrm{m}$, typically $\sim 1 \mu \mathrm{m}$. They may be straight, kinked, hooked or forked and some are reported to be hollow. Their outer surfaces are usually grooved. The mechanism of Sn, Cd, Zn, and other metal whisker growth has been studied for many years.

A single accepted explanations of this mechanism has not been established, but there are some commonly agreed upon factors involved in whisker formation. Tin $(\mathrm{Cd}, \mathrm{Zn}$, etc.) whisker growth is primarily attributed to stresses in electrolytic plating. Whiskers appear to grow more readily at temperatures approaching $50^{\circ} \mathrm{C}$ and to cease growing at temperatures higher than about $140^{\circ} \mathrm{C}$ and lower than around $-40^{\circ} \mathrm{C}$.

Metal whiskers growing from electroplated metals pose a serious reliability risk to electronic assemblies. Several instances have been reported where tin whiskers have caused system failures. Whiskers or parts of whiskers may break loose and bridge isolated conductors. In low voltage, high impedance circuits, there may be insufficient current available to fuse the whisker open, which results in a stable short circuit. 
However, this type of growth is not a corrosion induced process neither it requires any other elements present as catalysts [10].

Whiskers described in this section grow spontaneously without an applied electric field or moisture (unlike dendrites) and independent of atmospheric pressure (they grow in vacuum). Whisker growth may begin soon after plating or may take years to initiate.

\section{GROWTH OF SILVER WHISKERS IN CORROSIVE ATMOSPHERE}

Though hazardous phenomenon has been seen from 1920s and caused a number of violent failures, but it was practically neither studied nor clearly understood. Only few papers describe extensive silver whiskers' growth found at synthetic fiber factory in France [11], Kraft linerboard mill in southeastern USA [12], and Coking plant in UK [13]. In all these locations Hydrogen Sulfide was present in atmosphere.

The first and only extensive study of silver whiskers was prompted by the failures in a synthetic fiber factory [11] twenty years ago. Atmosphere in the factory had $\mathrm{H}_{2} \mathrm{~S}$ level of several dozens ppm, which is very high. No other contaminants, such as pure sulfur and $\mathrm{SO}_{2}$, have been found. As later confirmed by analysis, contaminated pieces have been heavily sulphurated, Improved ventilation of the premises did not bring the expected results, and although the level of $\mathrm{H}_{2} \mathrm{~S}$ was reduced to $0.5 \mathrm{ppm}$, incidents began again.

In the course of thorough periodic examination of the suspect equipment "metallic" looking filaments, some more than 0.4 in $(1 \mathrm{~cm})$ long, were observed on the supports of certain fuse-holders. In some cases large numbers of very fine filaments appeared in tufts, in others they looked like needles growing at right angles to the metallic surface.

This phenomenon was found not only on silver plated copper parts but also on contacts made of $\mathrm{AgNi}$ alloy. The filaments grew most readily on outside edges and corners near contact zones, but not necessarily on the points thought to be the hottest.

Silver whisker growth was reproduced in laboratory setup [11], in which the different level of $\mathrm{H}_{2} \mathrm{~S}$ (50 ppm than $1 \mathrm{ppm}$ ) was maintained and the temperature of the sample was measured. Temperature of the chamber was stabilized at $40{ }^{\circ} \mathrm{C}$ and relative humidity was $40 \%$. The test was carried out on a triple-pole fuse-holder, whose poles, linked in series, had a current corresponding to the nominal intensity of the apparatus (50 amp) passing through it. The supports of the fuse-holders were made of copper, electroplated with silver $10 \mu \mathrm{m}$ thick. The cylindrical ends of the fuses were also silver-plated. In the course of experiment it was found that the whiskers started to grow as soon as a fairly thick layer of silver sulfide is formed on the silver-plated parts. The only difference in $\mathrm{H}_{2} \mathrm{~S}$ level of $20 \mathrm{ppm}$ or $1 \mathrm{ppm}$ was that the formation of corrosion film takes longer for lower level of gas.

When temperature stayed under about $140{ }^{\circ} \mathrm{C}$ no filament growth was observed on the fuse-holder except typical $\mathrm{Ag}_{2} \mathrm{~S}$ crystals whose length did not exceed a few $\mu \mathrm{m}$. As soon as the temperature of the support rose above $140{ }^{\circ} \mathrm{C}$ in a matter of hours minuscule 
filaments began to appear. In 24 hours, these filaments had grown to $10 \mathrm{~mm}$. They looked exactly like the filaments on the apparatus in the factory. Each filament was made up of a bunch of fibers of about $1 \mu \mathrm{m}$ in diameter. The diameter of the filaments measured at the base varied between 10 to $70-80 \mu \mathrm{m}$. The sections where the filaments seem to grow best were on the outside edges and corners. The speed at which filaments grew in these conditions reached about $1 \mathrm{~mm}$ per hour, that is $0.3 \mu \mathrm{m} / \mathrm{s}$. The whiskers were made of $\mathrm{Ag}$ and $\mathrm{S}$ but with much less sulfur than there is in $\mathrm{Ag}_{2} \mathrm{~S}$. It was assumed in [11] that silver whiskers have been partially transformed into silver sulfide covering filament surfaces exposed to an ambient $\mathrm{H}_{2} \mathrm{~S}$.

Another observation given in [12] is that under proper conditions there is no restriction to the length that the whisker could grow. There are other facts showing that silver whiskers may grow at room temperature as well.

In [13] the sample was laid on the bench in a laboratory and subjected to heavy concentration of several corrosive gases, including hydrogen sulfide, at ambient temperature. Some time later it was found that whiskers up to $4 \mathrm{~mm}$ in length had developed.

The role of silver plating thickness in silver corrosion was studied in [14]. The test was performed on three sets of model contacts pre-corroded for 1,5 and 10 days respectively in atmosphere containing a mixture of $\mathrm{Cl}_{2}, \mathrm{NO}_{2}$ and $\mathrm{H}_{2} \mathrm{~S}$ (Battelle class III). Contacts were made from copper electroplated with 2, 5 and $20 \mu \mathrm{m}$ silver. Then precorroded contacts were powered and tested under normal force. It was found that the whiskers start to grow from corrosion layer formed in atmosphere containing $\mathrm{H}_{2} \mathrm{~S}$ concentration as low as $0.1 \mathrm{ppm}$. With the thinnest silver coating $(2 \mu \mathrm{m})$ covered with the thickest corrosion film (10 days in Battelle chamber) silver whiskers formed just outside the conducting area of the anode in the 15 minutes test. At the time the whiskers were forming, the temperature of the contacts was close to $160{ }^{\circ} \mathrm{C}$.

The role of base material in whisker growth is not clear yet. Silver whiskers are found growing not only on silver plated copper but also on Ag90/Ni10 alloy [11]. In [14] whiskers' formation was observed on coupons made of silver with purity $99.9-99.99 \%$. In this experiment silver coupons were exposed to atmosphere containing $3 \mathrm{ppm}_{2} \mathrm{~S}$ at 40 ${ }^{\circ} \mathrm{C}$ and $80-85 \%$ relative humidity.

The effect of silver sulfide film thickness on the start for whiskers to grow was studied in [15]. Until the thickness of silver sulfide film reached $0.075 \mu \mathrm{m}$ (750 $\AA$ ), none of the whiskers have been found. Such thickness of tarnish film is built in 1 week on silver exposed to $20 \mathrm{ppm}_{2} \mathrm{~S}$ at room temperature in humid air (75\% relative humidity).

The influence of other than $\mathrm{H}_{2} \mathrm{~S}$ gases present in atmosphere on silver sulfide formation is not thoroughly investigated. Though it was shown in [16] that the presence of $\mathrm{NO}_{2}$ greatly enhances silver corrosion rate, which was 5 times faster than expected when the combination $\mathrm{H}_{2} \mathrm{~S}$ and $\mathrm{NO}_{2}$ was present in atmosphere. However two fast 
corrosion process would consume silver plating completely way before the whiskers may develop.

Summary. Based on observations and experiments described in [9-16], several factors, which initiate and accelerate the growth of silver whiskers may be determined. It is obvious that $\mathrm{H}_{2} \mathrm{~S}$ gas even of very low level is a primary factor to initiate the whiskers' growth. A layer of silver sulfide $\left(\mathrm{Ag}_{2} \mathrm{~S}\right)$ of certain thickness needs to be formed for whiskers to start growing.

Elevated temperature (above $140{ }^{\circ} \mathrm{C}$ ) of the parts seems to accelerate the growth. The influence of other factors on whiskers' growth such as type of base material or elevated humidity is not defined yet. In general, there is no clear understanding of the origin of the silver whisker phenomenon yet and the forces that make them grow are not defined.

The following research has the primary goal to define the chemical composition and morphology of the whiskers, and the ranges of the whisker size. This study will be followed by laboratory experiment focused on the role of various environmental parameters and plating properties to get closer to understanding of this unique phenomenon.

\section{EXPERIMENTAL STUDY OF SILVER WHISKERS}

\section{A. History of the Failure}

The growth of silver whiskers was first found on corroded silver plated parts of low voltage circuit breakers being in service in the control room of a pulp plant in Duluth, MN. It happened in one year after the factory switched from one pulp processing technology to another one. The last process was based on the use of the chemical reaction producing $\mathrm{H}_{2} \mathrm{~S}$. The level of $\mathrm{H}_{2} \mathrm{~S}$ in control room was in the range 0.5-2 ppm.

Since then every 2-3 months the electric service group at the plant performed cleaning of the units subjected to extensive corrosion and whiskers' growth (Fig. 1). Two units, which have been thoroughly cleaned in May 2000, failed in July 2000 just two month after previous maintenance (Fig. 2).

We collected the samples of silver whiskers from heavily corroded circuit breakers during scheduled overhauls or after thermal failures in May-August 2000. The clumps of the whiskers found inside current carrying path of the breaker after failure in July 2000

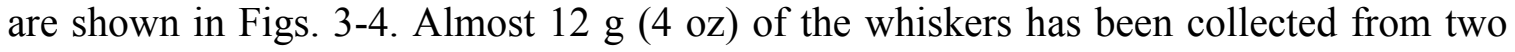
low voltage breakers. The period during which they grew before failure was only two months.

\section{B. Visual Appearance of the Whiskers}

Most of the whiskers have a shape of a single thick thread, which may eventually split into several thinner filaments. The filaments have many different colors, shapes and sizes 
ranging from tiny thin "dawn"-looking formations to thick and strong threads, which are bound together into large tufts and clumps (Figs. 3, 4).

Under high magnification various groups and agglomerations have been found, but most of them look like a group of long threads, which may eventually split into several thinner filaments.

The colors of the whiskers range from shiny silver and gold luster to dull dark gray or black. The color of some whiskers changes along the length of the filament from bright silver to bright yellow or from metallic luster to dark dull gray or black.

\section{Morphology and Chemical Composition of the Whiskers}

The morphology of the whiskers was studied by using Scanning Electron Microscopy (SEM). Chemical composition of the whiskers was determined by Energy Dispersive Xray Spectroscopy (EDS).

1) Morphology: The samples for SEM analysis were selected from whisker clumps under stereo microscope magnification. SEM photographs of the whiskers at high magnification are presented in Figs. 5-8.

Pictures in Figs. 5 and 6 show the whiskers at the very beginning of the growth. They start to extrude from the flakes as a group of many thin straight or curly filaments of different thickness, which may then fuse together into a thick filament.

Some filaments are bound together forming agglomerates, such as a curly miniature "pig tail" (Fig. 7). The thickness of the whiskers varies from 2-4 $\mu \mathrm{m}$ to almost $1000 \mu \mathrm{m}$ ( $1 \mathrm{~mm}$ or $0.04 \mathrm{in}$ ). Some of the whiskers are as long as $5-10 \mathrm{~cm}$ (up to $4 \mathrm{in}$ ).

The color of the whisker surface seems to correlate very well with the surface morphology. The surface of two whiskers, one with metallic luster (Fig. 9) and another one having dull dark color (Fig. 10) is significantly different. Various types of whisker growth from the corrosion flakes are shown in Fig. 11 and 12.

2) Chemical composition: X-ray analysis of chemical composition of the whiskers is presented in Table 1 with the data given in weight (wt) percent. All data presented in the table characterize elemental composition of relatively thin upper layer of the whisker, since EDS techniques provides quantitative analysis with a sampling depth of 1-2 $\mu \mathrm{m}$.

Whiskers (\#1-16) with silver luster are made of silver with the content of silver from 94 $\%$ to $99.4 \%$. Some of the whiskers with silver luster contain up to $4.5 \%$ of copper. The whiskers (\#17-20) with yellow luster have higher content of copper (from $7 \%$ to $33 \%$ ).

Chemical composition of whisker \#16 with silver luster (one of the group shown in Fig. 8 ) was measured along the length of the whisker. The points for the measurements have been selected at the distance 1-2 $\mathrm{mm}$ from each other. The composition of the silver 
thread is quite stable. Silver content varies from $97.3 \%$ to $99.4 \%$. The other two elements copper and sulfur, are present in narrow range from traces to $1.4 \%$.

TABLE 1

Chemical composition of the whiskers

\begin{tabular}{|c|c|c|c|c|c|c|c|c|c|}
\hline $\mathrm{N}$ & $\begin{array}{c}\text { Sample } \\
\text { Description }\end{array}$ & $\begin{array}{l}\mathrm{Ag}, \\
\mathrm{wt} \% \\
\end{array}$ & $\begin{array}{r}\mathrm{Cu}, \\
\mathrm{wt} \% \\
\end{array}$ & $\begin{array}{c}\mathrm{S} \\
\mathrm{wt} \% \\
\end{array}$ & $\mathrm{~N}$ & $\begin{array}{c}\text { Sample } \\
\text { Description }\end{array}$ & $\begin{array}{c}\mathrm{Ag}, \\
\mathrm{wt} \%\end{array}$ & $\begin{array}{c}\mathrm{Cu}, \\
\mathrm{wt}^{0} \% \\
\end{array}$ & $\begin{array}{c}\mathrm{S}, \\
\mathrm{wt} \% \\
\end{array}$ \\
\hline 1 & $\begin{array}{c}\text { Whisker \#1 } \\
\text { (silver) }\end{array}$ & 99.44 & 0.44 & traces & 16 & $\begin{array}{c}\text { Whisker \#21, } \\
\text { point } 1\end{array}$ & 99.38 & 0.51 & traces \\
\hline 2 & $\begin{array}{c}\text { Whisker \#2 } \\
\text { (silver) }\end{array}$ & 99.38 & 0.51 & traces & $16 a$ & $\begin{array}{c}\text { Whisker \#21, } \\
\text { point } 2 \\
\end{array}$ & 99.40 & 0.42 & traces \\
\hline 3 & $\begin{array}{c}\text { Whisker \#3 } \\
\text { (silver) }\end{array}$ & 99.26 & 0.59 & traces & $16 b$ & $\begin{array}{c}\text { Whisker } \# 21 \text {, } \\
\text { point } 3\end{array}$ & 99.29 & 0.30 & 0.41 \\
\hline 4 & $\begin{array}{c}\text { Whisker \#4 } \\
\text { (silver) }\end{array}$ & 98.41 & 1.39 & traces & $16 \mathrm{c}$ & $\begin{array}{c}\text { Whisker \#21, } \\
\text { point } 4\end{array}$ & 98.07 & 1.34 & 0.59 \\
\hline 5 & $\begin{array}{l}\text { Whisker \#5 } \\
\text { (silver), Fig.9 }\end{array}$ & 98.32 & 0.93 & 0.75 & $16 \mathrm{~d}$ & $\begin{array}{c}\text { Whisker \#21, } \\
\text { point } 5\end{array}$ & 98.38 & 1.24 & 0.38 \\
\hline 6 & $\begin{array}{c}\text { Whisker \#6 } \\
\text { (silver) }\end{array}$ & 98.29 & 1.61 & traces & $16 \mathrm{e}$ & $\begin{array}{c}\text { Whisker \#21, } \\
\text { point } 6\end{array}$ & 99.69 & 0.07 & 0.24 \\
\hline 7 & $\begin{array}{c}\text { Whisker \#7 } \\
\text { (silver) }\end{array}$ & 97.53 & 1.52 & 0.95 & $16 f$ & $\begin{array}{c}\text { Whisker \#21, } \\
\text { point } 7 \\
\end{array}$ & 97.27 & 1.42 & 1.37 \\
\hline 8 & $\begin{array}{c}\text { Whisker \#8 } \\
\text { (silver) }\end{array}$ & 96.93 & 2.75 & traces & $16 \mathrm{~g}$ & $\begin{array}{c}\text { Whisker } \# 21 \text {, } \\
\text { point } 8\end{array}$ & 99.27 & 0.42 & 0.31 \\
\hline 9 & $\begin{array}{c}\text { Whisker \#9 } \\
\text { (silver) }\end{array}$ & 96.33 & 3.22 & 0.45 & $16 \mathrm{~h}$ & $\begin{array}{c}\text { Whisker \#16 } \\
\text { (yellow) }\end{array}$ & 92.3 & 6.7 & 1.0 \\
\hline 10 & $\begin{array}{c}\text { Whisker \#10 } \\
\text { (silver) }\end{array}$ & 96.30 & 2.28 & 1.42 & 17 & $\begin{array}{c}\text { Whisker \#17 } \\
\text { (yellow) }\end{array}$ & 91.14 & 8.55 & traces \\
\hline 11 & $\begin{array}{c}\text { Whisker \#11 } \\
\text { (silver) }\end{array}$ & 96.19 & 2.28 & 0.83 & 18 & $\begin{array}{c}\text { Whisker \#18 } \\
\text { (yellow) }\end{array}$ & 90.91 & 8.94 & traces \\
\hline 12 & $\begin{array}{c}\text { Whisker \#12 } \\
\text { (silver) }\end{array}$ & 95.82 & 3.24 & 0.94 & 20 & $\begin{array}{l}\text { Whisker \#19 } \\
\text { (yellow end) }\end{array}$ & 70.69 & 27.50 & 1.81 \\
\hline 13 & $\begin{array}{c}\text { Whisker \#13 } \\
\text { (silver) }\end{array}$ & 94.78 & 3.64 & 1.58 & 22 & $\begin{array}{l}\text { Whisker \#19 } \\
\text { (dark end) }\end{array}$ & 62.44 & 33.09 & 4.47 \\
\hline 14 & $\begin{array}{c}\text { Whisker \#14 } \\
\text { (silver) }\end{array}$ & 94.38 & 4.26 & 1.36 & 23 & $\begin{array}{l}\text { Whisker \#20 } \\
\text { (dark), Fig.10 }\end{array}$ & 72.30 & 18.20 & 9.11 \\
\hline 15 & $\begin{array}{c}\text { Whisker \#15 } \\
\text { (silver) }\end{array}$ & 94.32 & 3.90 & 1.78 & & & & & \\
\hline
\end{tabular}

The content of sulfur on the surface of the whiskers varies from traces of sulfur (whiskers with metallic luster) and up to $9 \%$ (whiskers with dull dark color), which is enough to constitute a pure silver sulfide on the surface of the whisker. Whisker \#19 has one yellow end and the other end is dark, which is characterized by growing content of sulfur along the whisker changing from $1.8 \%$ for yellow end to $\sim 4.5 \%$ for dark end.

Chemical composition of the whiskers correlates very well with the color and surface morphology of the whiskers. The whisker (\#5) surface shown in Fig. 9 contains less than $1 \%$ of sulfur. The darker whiskers have more sulfur on the surface than the whiskers with metallic luster, probably because they were longer exposed to atmosphere contaminated with $\mathrm{H}_{2} \mathrm{~S}$. The surface of one of such whisker (\#20) shown in Fig. 10 contains more than $9 \%$ of sulfur. 
Composition of the whiskers is compared with the composition of the flakes collected from the surfaces of the corroded conductive parts of the breaker. The flakes contain silver, copper and sulfur in proportions corresponding to the mixture of silver and copper sulfides.

3) Chemical composition of the whisker's cross section: One of the samples for X-ray analysis was prepared to determine internal composition of the whisker. The sample was cut through the base metal, thick corrosion layer and small whisker growing from corrosion layer (Fig. 13).

Chemical composition of all three components of the sample is presented in Table 2. The composition was measured from the base metal across corrosion layer and along the cross section of the whisker.

Silver content changes across the border between corrosion layer and whisker drastically from $\sim 3 \%$ in corrosion layer to $100 \%$ in whisker's body (see graph in Fig.14).

TABLE 2

Atomic composition profile of the sample (Fig. 9).

\begin{tabular}{|l|l|l|l|l|}
\hline $\mathrm{N}$ & Sample Description & $\mathrm{Ag}, \mathrm{wt} \%$ & $\mathrm{Cu}, \mathrm{wt} \%$ & $\mathrm{~S}, \mathrm{wt} \%$ \\
\hline 1 & Base metal & & 100.0 & \\
\hline 2 & Corrosion layer & 2.9 & 86.3 & 10.7 \\
\hline 3 & Whisker, at border line & 100.0 & -- & -- \\
\hline 4 & Whisker, middle & 100.0 & -- & -- \\
\hline 5 & Whisker, at far end & 100.0 & -- & -- \\
\hline
\end{tabular}

\section{MEANS TO CONTROL SILVER CORROSION AND WHISKERS' GROWTH}

The following recommendations are focused on the means helping to decrease silver corrosion, which initiates and supports the growth of the whiskers. The other means are considered to control the factors that most possibly accelerate this phenomenon.

\section{A. Hydrogen Sulfide Chemical Filtration}

Silver corrosion would be significantly diminished or slow down if the concentration of Hydrogen Sulfide in separate power control rooms of industrial facilities could be minimized as much as possible. The air conditioning could be much more effective if being fitted with activated carbon filters, which are housed in a separate box about the size of one of the air conditioning units. This method may reduce harsh environment level to $\mathrm{H}_{2} \mathrm{~S}$ concentration of $3 \mathrm{ppb}$.

It will not entirely eliminate corrosion and eventually whiskers might grow, but it may significantly slow down the process of silver sulfide layer formation. The unit does require some maintenance and the filters have to be changed approximately once a year. 
The next level of protection is to fit individual active carbon filters over all switchgear louvers. These individual filters are disposable and can do a good job of filtering whatever portion of the air that goes through the louvers, but it will not protect the equipment in the instrument compartment or cubicles where there is not a definite air entry, so their overall effectiveness is limited.

\section{B. Contact Lubrication}

Sealing out corrosive gases can help to protect metal surfaces against atmospheric corrosion. Corrosion inhibitors/lubricants applied at any sliding contact points and surfaces will do this job very well. Special attention should be given to the correct choice of these products to not induce interference with electrical properties of conductive parts. Effective lubricant for electrical parts should be chemically inert towards the metal surfaces to be lubricated. Lubricants used on silver-plated surfaces should not carry sulfur-containing compounds.

Lubricants for electrical parts should not collect dust and particulate matter, should be resistant to oxidation and chemically inert to corrosive atmospheric components. These lubricants should not build non-conductive deposits on contact surfaces after multiple operations and retain long-term thermal stability at least up to $400{ }^{\circ} \mathrm{F}$. Any corrosion inhibitor must be thoroughly tested for electrical application $[17,18]$.

Electrical contacts should not be lubricated with metal filled lubricants unless tested and proved to be effective long term. Many can accelerate corrosion, create conductive paths and eventually cause failure. The general rule is to avoid lubricants containing graphite, Molybdenum Disulfide $\left(\mathrm{MoS}_{2}, \mathrm{Moly}\right)$, or PTFE (Teflon $\left.{ }^{\circledR}\right)$ for electrical contacts, because they could cause a resistance rise after multiple operations [19].

\section{Vapor Corrosion Inhibitors (VCI)}

Another technique to protect silver plated surfaces from the contact with atmosphere is to apply so called Vapor Corrosion Inhibitors (VCI). VCI are chemicals, which form a protective invisible layer deposited on components, parts and finished assemblies. A full range of corrosion inhibitors is developed to protect ferrous and non-ferrous metals, including formulations that protect combinations of metals [20]. VCI emitters may provide long term protection against various corrosion conditions including salt, moisture, and corrosive gases. Vapor Corrosion Inhibitors may slow down a corrosion of silver-plated copper parts in switchgear in atmospheres containing over $200 \mathrm{ppm}$ of mixed gases such as $\mathrm{SO}_{2}, \mathrm{H}_{2} \mathrm{~S}, \mathrm{HCl}$, etc.

There is temperature limit of using this technique, since the higher temperature, the faster the VCI evaporates. At an operating temperature of $120{ }^{\circ} \mathrm{F}$ to $140{ }^{\circ} \mathrm{F}$ the useful lifetime will start decreasing, and if they are used continuously at elevated temperature containers emitting VCI should be replaced more often than once in every two years. 


\section{Silver plating thickness}

The role of Silver plating thickness in corrosion process might be very important. It was shown [3] that when silver coating thickness increases a total corrosion film thickness decreases and corrosion film contains less copper. First, these changes lead to dramatic decrease in contact resistance. Secondly, the build-up of silver sulfide thick enough to start the growth of the whiskers might be significantly slow down. Therefore thickness of silver coating is a very important factor in the reliability of contacts in environments that are corrosive for both silver and copper.

The copper creep corrosion film is thought to be very detrimental to silver plated contacts mainly due to a higher growth rate in comparison with silver corrosion films. Thick pore-free silver coating with the thickness of about $20 \mu \mathrm{m}$ is recommended to avoid influences of the copper substrate on the corrosion mechanism.

\section{E. Alternate Plating}

Corrosion induced growth of the filaments on other than silver metals have not been seen yet. Therefore the use of other than silver plating may eliminate whisker problem. Substituting silver with expensive gold plating might not be a good solution. There are difficulties with this strategy, since many control switches and protective relays are not available with gold plated contacts.

Tin plating has other problems, such as much higher resistance than silver, galling, and softness that makes it less than ideal for sliding contact applications. However, in [12] tin plating was recommended instead of silver for use on electrical equipment for the paper industry, on current carrying parts of contactors and breakers, on the stabs and stab mating fingers, everywhere except arcing contacts.

When choosing Tin for plating in very aggressive atmosphere it is useful to follow the "Tin Commandments" developed by Whitley [21]. It is considered to be poor practice to use pure tin plating on contacts because of whiskers, which develop on the surface no matter if there is atmosphere or vacuum.

The use of Tin alloys with $5 \%$ or less of lead or other tin alloys is a practical solution to the whisker problems.

However, formation of tiny tin whiskers, reviewed in Section III, was neither found on current carrying parts of large size distribution apparatus with tin plating nor has been described in technical literature yet. [22].

\section{F. Temperature Control}

As follows from literature review and observations elevated temperature is one of the factors, which accelerate the process of silver corrosion and whisker growth. Therefore temperature control is essential for whisker phenomenon control. If the temperature of 
the electrical parts are maintained at relatively low level, below standard rated maximum operating temperature $\left(\sim 105{ }^{\circ} \mathrm{C}\right)$, the silver whiskers may still grow in $\mathrm{H}_{2} \mathrm{~S}$ contaminated area but at very slow rate.

There are two major factors, which lead to overheating. The first is corrosion process, when silver forms non-conductive silver sulfide deposit resulting in a highly resistant contact surface. With the increase in resistance, more heat is generated speeding up the chemical reaction of silver with $\mathrm{H}_{2} \mathrm{~S}$, which finally leads to thermal connection failure. The second factor is deterioration of the mechanical integrity of the components. It is very important to timely maintain mechanism to keep the contact pressure at critical points, such as between the stab and fingers, at designed level. Otherwise as the pressure decreases, the resistance will increase and depending on the current, more heat will be generated.

Condition-based maintenance supported by on-line circuit breaker condition monitoring and temperature control of current-carrying path in switchgear during operation can effectively protect electrical apparatus from the failure.

\section{CONCLUSIONS}

Thread-like formations called in literature "silver whiskers" spontaneously growing on copper parts plated with silver have been studied. The results of chemical analysis show, that the whiskers having silver metallic luster are made mostly of silver and may contain up to $4 \%$ of base metal copper. The whiskers with yellow metallic luster contain silver and from $8 \%$ to $30 \%$ of copper.

The surface of the silver whiskers is contaminated with silver sulfide at different degree, and amount of this contamination most possibly depends on how long these whiskers have been exposed to atmospheric $\mathrm{H}_{2} \mathrm{~S}$. Dark whiskers are the most corroded ones containing significant amount of sulfur (up to $9 \%$ ).

The size and the color of the filaments may depend on the age of whiskers. Although the whiskers of the same size may have different colors, either with silvery and yellow metallic luster or being dark and dull. Some whiskers change color and composition along the length of the filament.

The temperature seems to be the major accelerating factor of the growth. Therefore the difference in the color and composition of the long and thick whiskers may be explained with different temperature conditions of whisker "birth place". The silvery whiskers could grow much faster in the hotter areas of the breaker and be exposed to $\mathrm{H}_{2} \mathrm{~S}$ for a shorter period of time than the same size whiskers, which grew slower in cooler locations. The last whiskers have been longer exposed to corrosive gas, which led to formation of the surface layer of silver sulfide having dark color.

The most important conclusion is that because silver whiskers are metallic formations they are highly conductive. Taking into consideration the rate of the growth, the size and 
amount of the whiskers developing practically everywhere, but mostly on corners and edges of conductive parts, including moving and stationary contacts and finger cluster, it is obvious that the consequences of the phenomenon are extremely dangerous.

Though the origin and the forces that initiate and support the growth of the whisker are not clearly defined yet, there are several means that may be recommended to slow down and control the growth of the highly hazardous formations.

Application of some of the proposed means at the pulp recycling plant where the whiskers, described in this paper, have been found completely resolved the problem [23]. Since September 2000 the factory does not experience corrosion problem and whiskers' growths has been eliminated.

In general, approach to selection of protective means is based on various practical observation and analysis of the factors, which usually present where the phenomenon takes place.

\section{ACKNOWLEDGMENT}

The author would like to thank David L. Swindler of Square D Company and John R. Thompson of StoraEnso for many valuable discussions and support in this work.

\section{REFERENCES}

[1] T.E. Graedel. "Corrosion mechanism for silver exposed to the atmosphere," $J$. Electrochem. Society, vol. 139, no. 7, pp. 1963-1970, July 1992.

[2] Metal Handbook, Ninth Edition, vol. 13. Corrosion, pp. 793, 1107, ASM International.

[3] T. Imrell, "The importance of the thickness of silver coating in the corrosion behavior of copper contact," Proc. $37^{\text {th }}$ IEEE Holm Conference On Electrical Contacts, pp. 237-243, 1991.

[4] S. C. Britton, "Spontaneous Growth of whiskers on tin coatings: 20 years of observation," Transactions of the Institute of Metal Finishing, vol. 52, pp. 95 - 102, April 3, 1974.

[5] G.A. Smith, "How to avoid metallic growth on electronic hardware," Circuits Manufacturing, pp.66 - 72, July 1977.

[6] D.R. Gabe, " Whisker growth on tin electrodeposits," Trans. IMF. vol. 65, p. 115, 1987.

[7] K.N. Tu, "Cu/Sn interfacial reactions: thin film case versus bulk case," Material Chemistry and Physics, vol. 46, p. 217-223, 1996. 
[8] B.-Z. Lee, D.N. Lee, "Spontaneous growth mechanism of tin whiskers," Acta Mater., vol. 46, n. 10, p. 3701-3714, 1998.

[9] P.L. Key, "Surface morphology of whisker crystals of tin, zinc and cadmium, " IEEE Electronic Components Conference, p. 155-157, May 1977.

[10] John R. Devaney, "Corrosion and dendrite growth and other metallurgical phenomena in microelectronic packages," Electronic Packaging and Corrosion in Microelectronics, Proc. Of ASM's Third Conference on Electronic Packaging: Material and Processes \& Corrosion in Microelectronics, p. 287-293, April 1987.

[11] J. Muniesa, "The growth of whiskers on Ag surfaces. Proc. International Conference on Electric Contact Phenomena, Pub. VDE-Verlag GmbH, Berlin, 1982, pp. 56-59, June 1982.

[12] Kenneth A. Riddle, "Tin plating versus silver plating and the use of silver alloys on electrical equipment for the paper industry," Conference record of 1990 Annual Pulp and Paper Industry Technical Conference, Seattle, WA, pp. 32-36, June 1990.

[13] E. Walker, Whisker Growth on Silver Tipped Contacts. Report on investigation of an electrical accident at Coking plant in 1979. UK Health and Safety Executive (HSE), UK British Standard Institute (BSI), 1999.

[14] A. K. Rudolphi, C. Bjorkman, T. Imrell, and S. Jacobson, "Conduction through corrosion films on silver plated copper in power contacts. Proc. 41st IEEE Holm Conference on Electrical Contacts, pp. 124-134, 1995.

[15] T. Tamai, "Ellipsometric analysis for growth of $\mathrm{Ag}_{2} \mathrm{~S}$ film and effect of oil film on corrosion resistance of Ag contact surfaces," Proc. 34th IEEE Holm Conference on Electrical Contacts, pp. 281-287, 1988.

[16] O. Muller, "Multiple contaminant gas effects on electronic equipment corrosion," Corrosion, v. 47, n. 2, pp.146-151, 1991.

[17] Paul Slade, Introduction to contact tarnishing and corrosion. In book "Electrical Contacts", ed. by Paul G. Slade, Marcel Dekker, Inc., 1999, pp.89-112.

[18] W. H. Abbott, Contact Corrosion. In book "Electrical Contacts", ed. by Paul G. Slade, Marcel Dekker, Inc., 1999, pp. 113-154.

[19] Arthur D. Crino, "The effects of exposed contact lubricants on the temperature rise of outdoor disconnect switches," Proceedings of the $63^{\text {rd }}$ Annual International Conference of Doble Clients, pp. 4-2.1-4-2.5, 1996. 
[20] P.J. Martin, W.B. Johnson, B.A. Miksic, "Corrosion inhibitors of electronic metals using vapor phase inhibitors. Proc. of NACE Conference, New Orleans, LA, paper No. 36, April 1984.

[21] J. Whitley, "The Tin Commandments," Connection Technology, April 27-28, 1989.

[22] M. Antler, Materials, Coatings and Platings. In book "Electrical Contacts", ed. by Paul G. Slade, Marcel Dekker, Inc., 1999, pp. 403-432.

[23] B.H. Chudnovsky, D.L. Swindler, John R. Thompson, "Silver Corrosion and Whiskers Growth on Power Contacts in Industrial Atmosphere of Pulp and Paper Plants," Conference Record of 2001 Annual Pulp and Paper Industry Technical Conference, pp.155-162, June 2001.

\section{VITA}

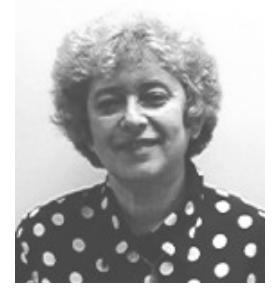

Bella H. Chudnovsky received her MS and Ph.D. degrees in Physics from the Rostov State University and RSU Research Institute of Physics in Russia. At Square D Company she conducts research in various application fields and develops new maintenance and refurbishment procedures and techniques for electrical apparatus. She is a member of IEEE, ASM, and APS. She has published over 40 articles and two monographs. 


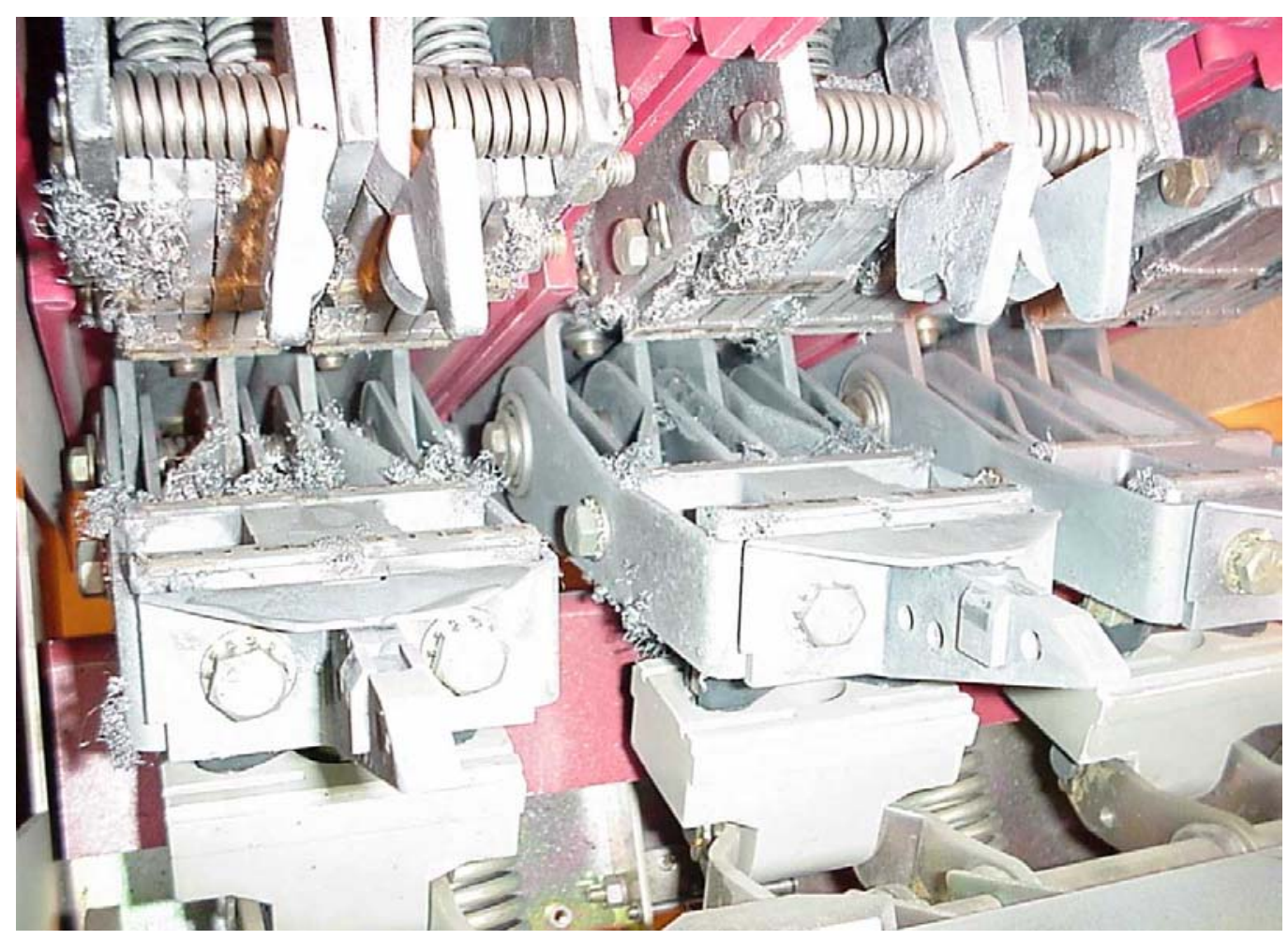

Fig.1. Silver whiskers inside circuit breaker in May 2000 (before cleaning)

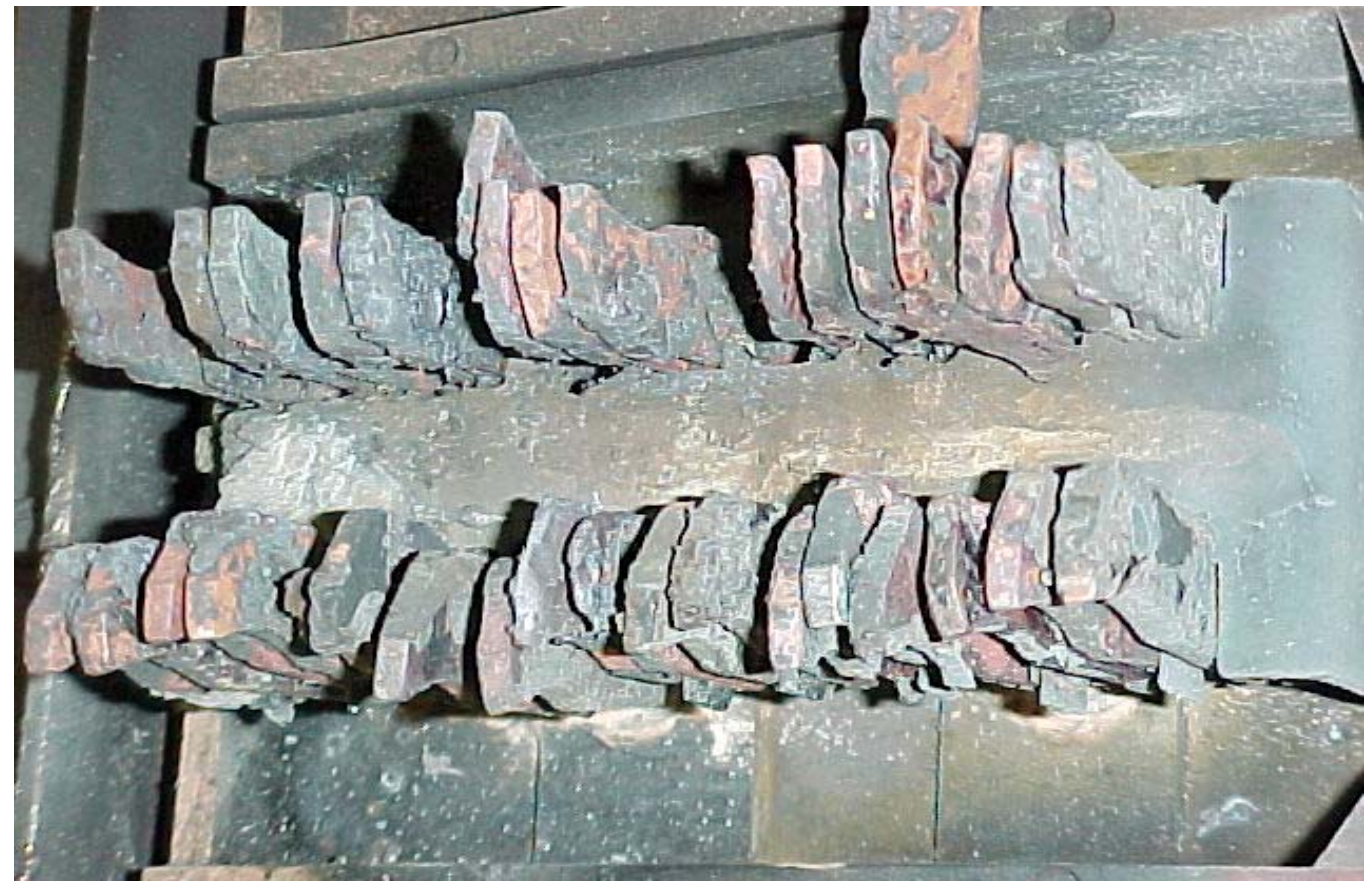

Fig.2. Finger Cluster after failure in July 2000 


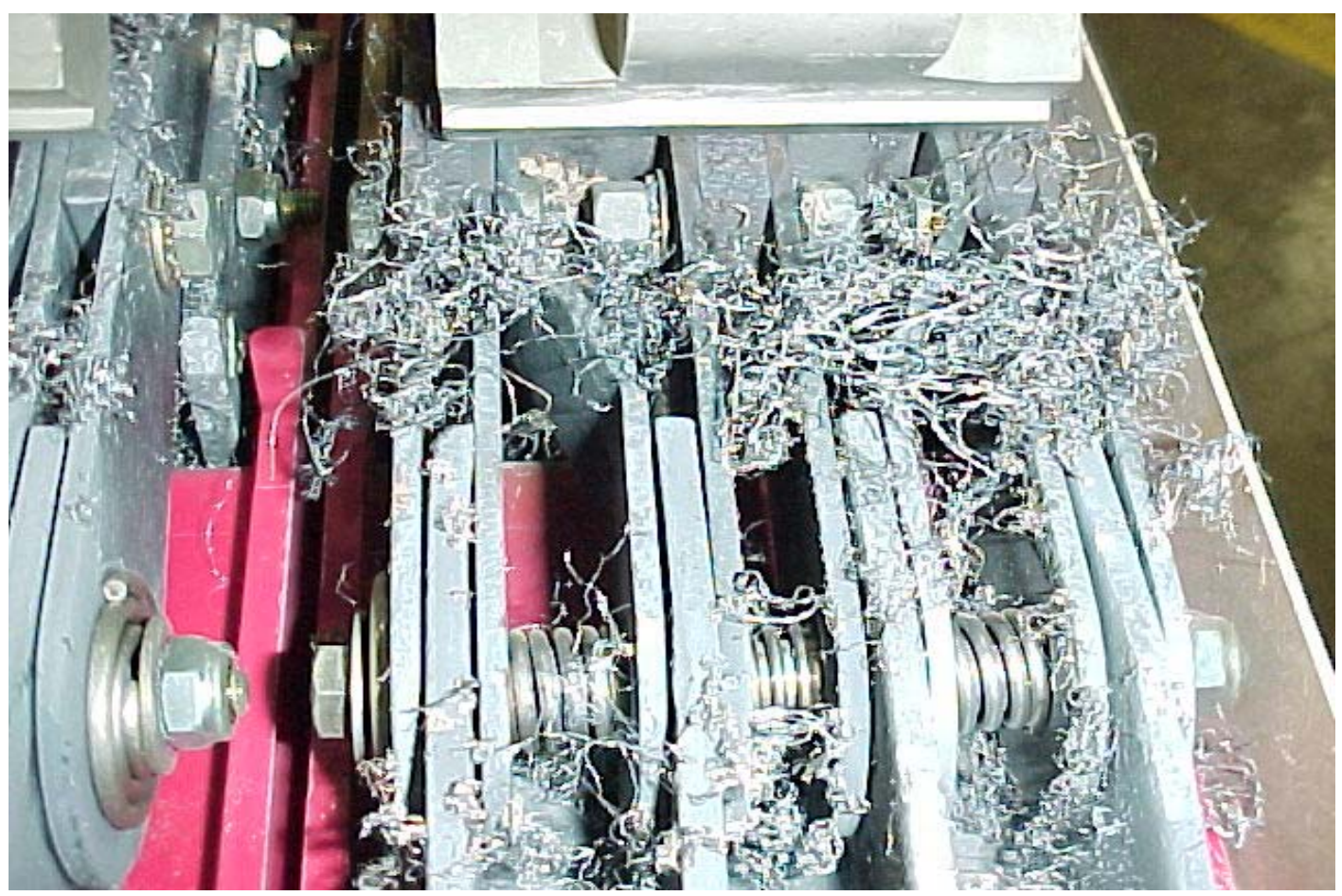

Fig. 3. Silver whiskers inside circuit breaker in July 2000 (after failure)

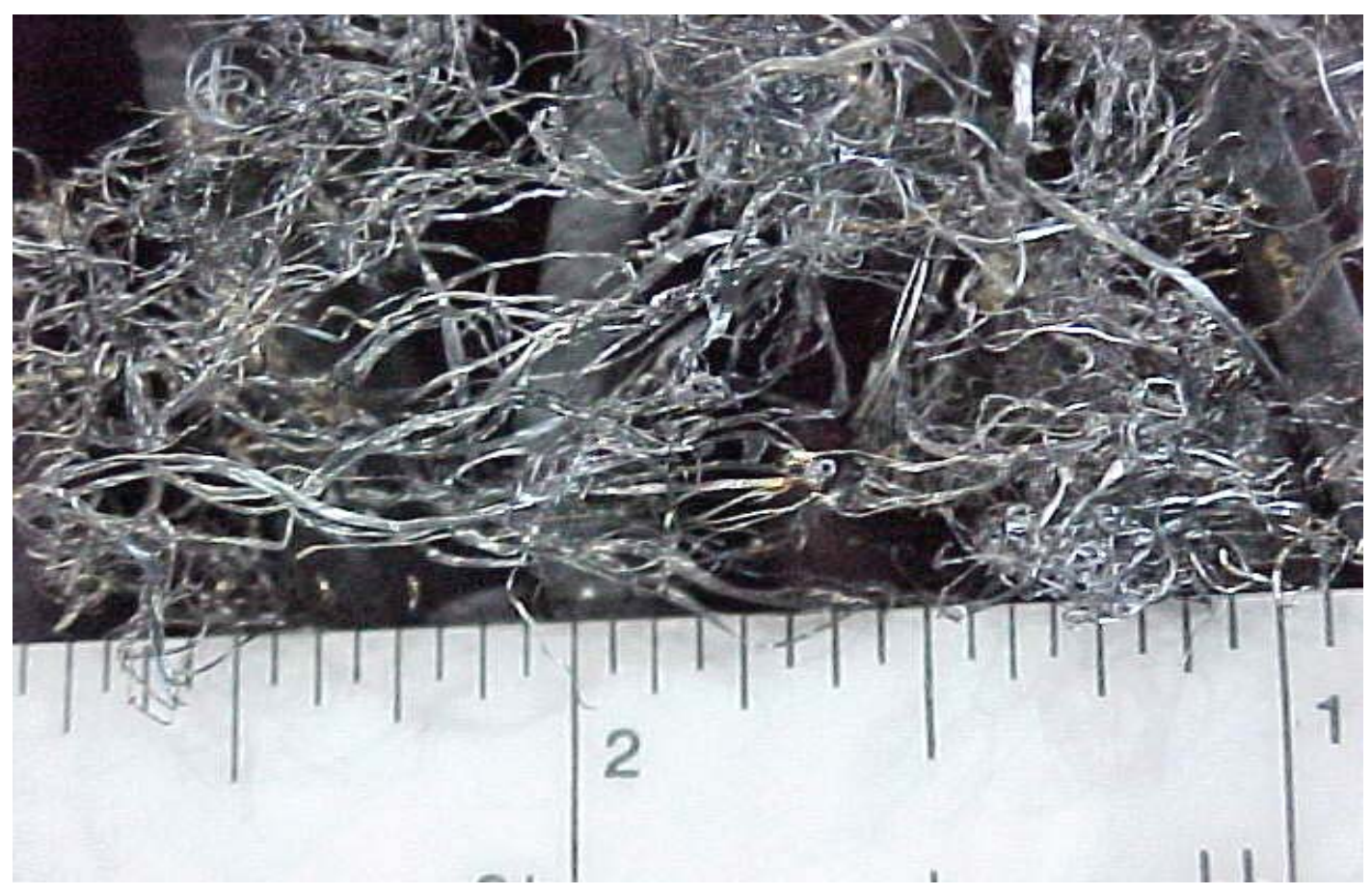

Fig. 4. Clump of two-month old silver whiskers 


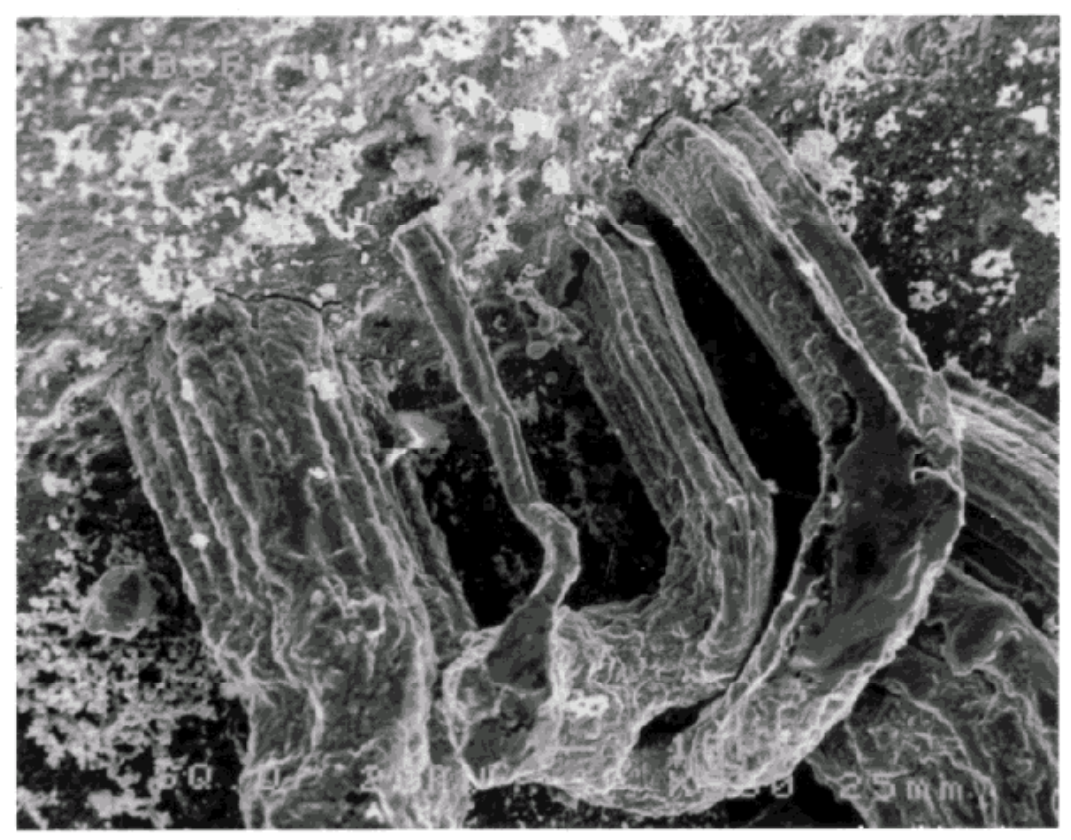

Fig. 5. Newborn silver whiskers, x500

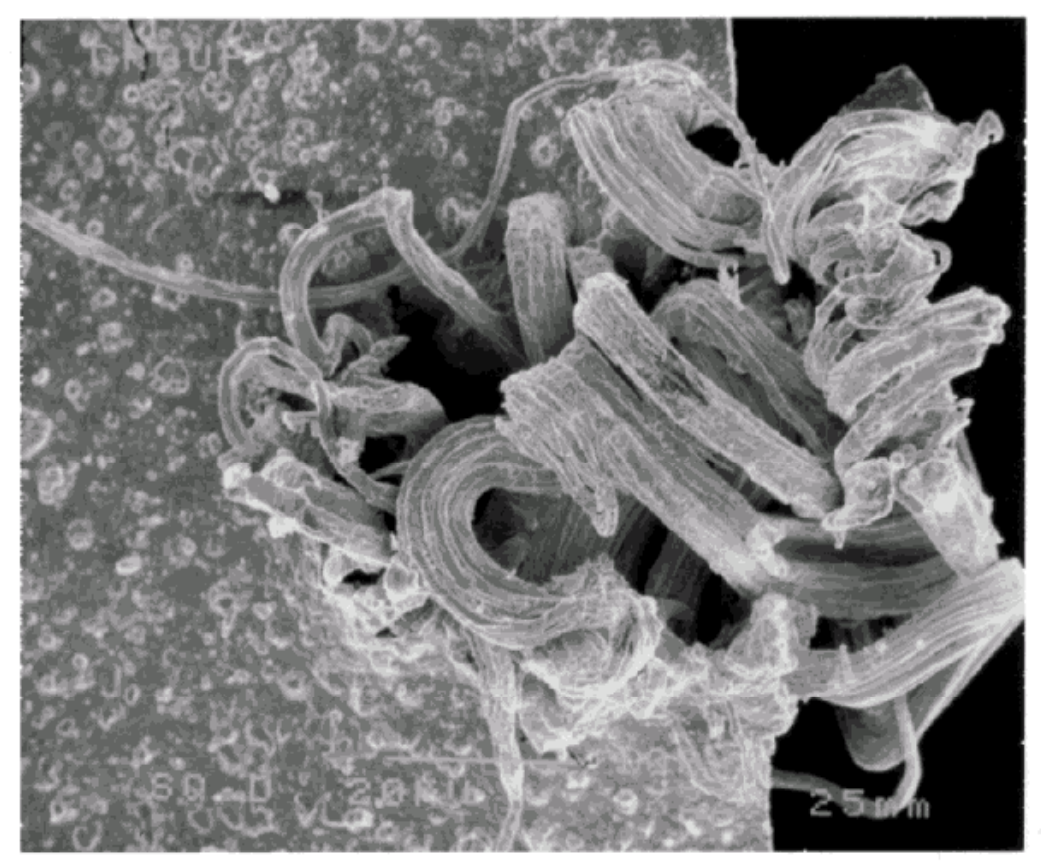

Fig. 6. Newborn silver whiskers, x350 


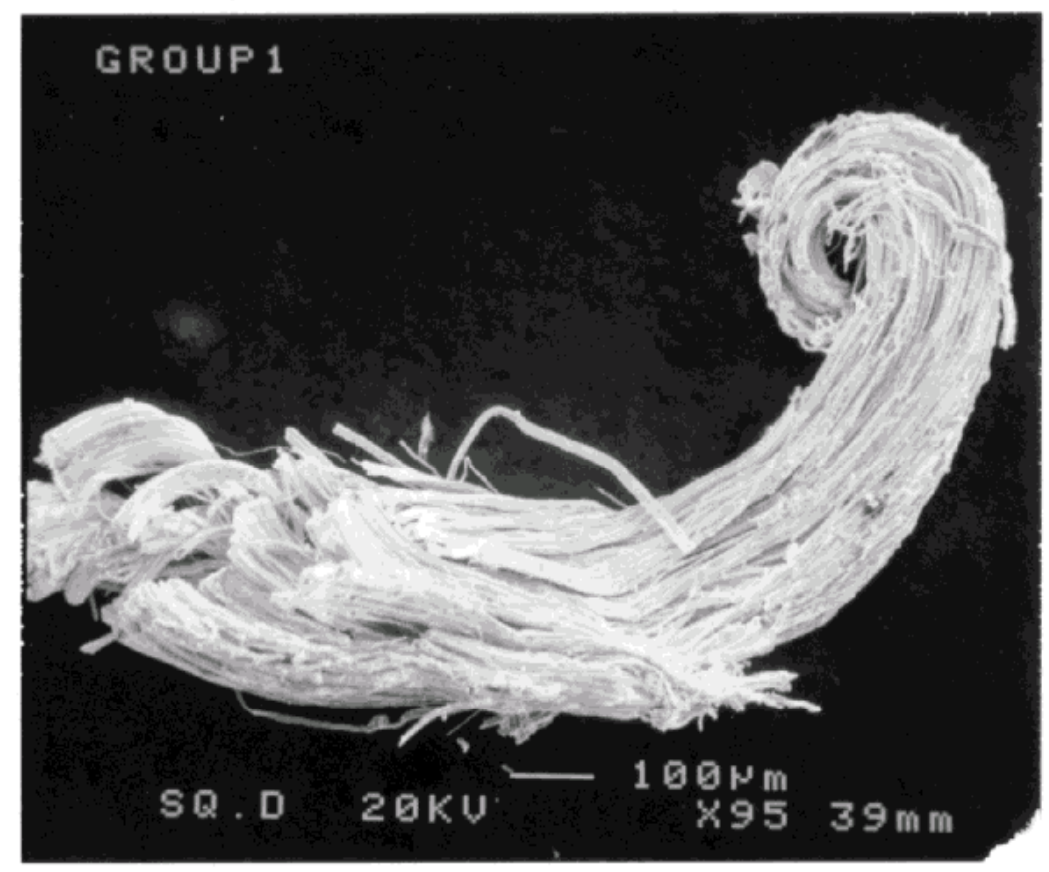

Fig. 7. Yellow whisker shaped as a "pig tail", x95

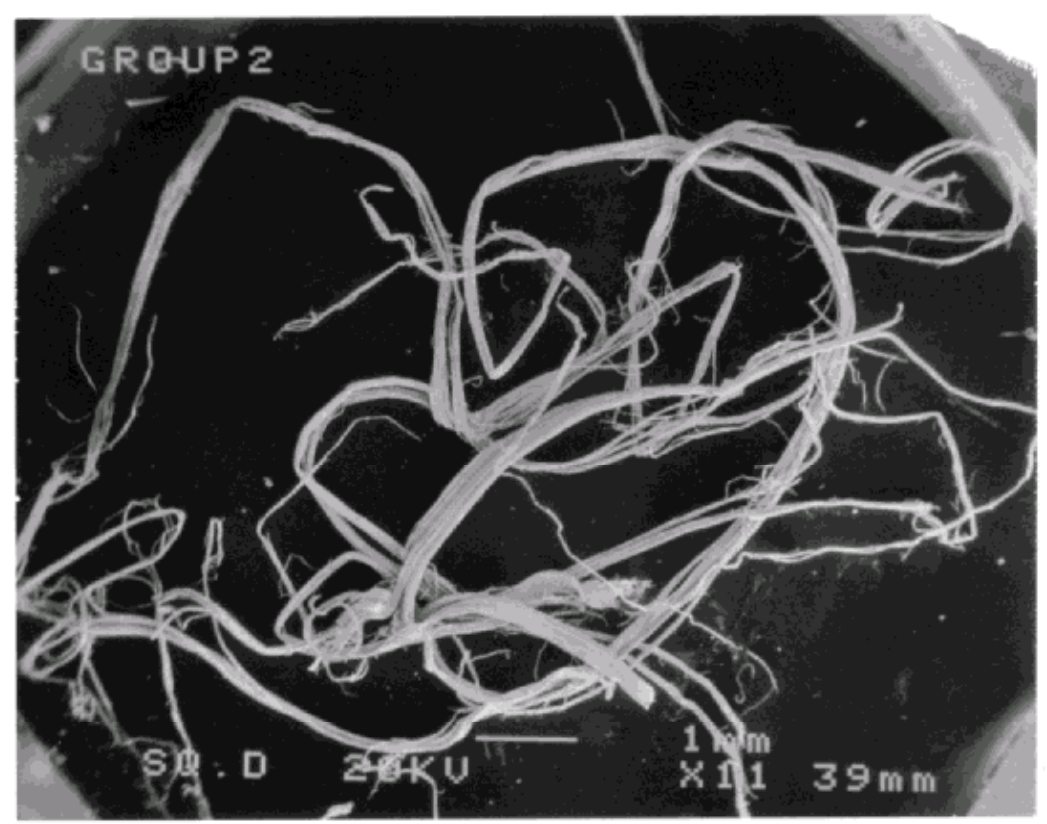

Fig. 8. Whiskers with silver luster, x11 


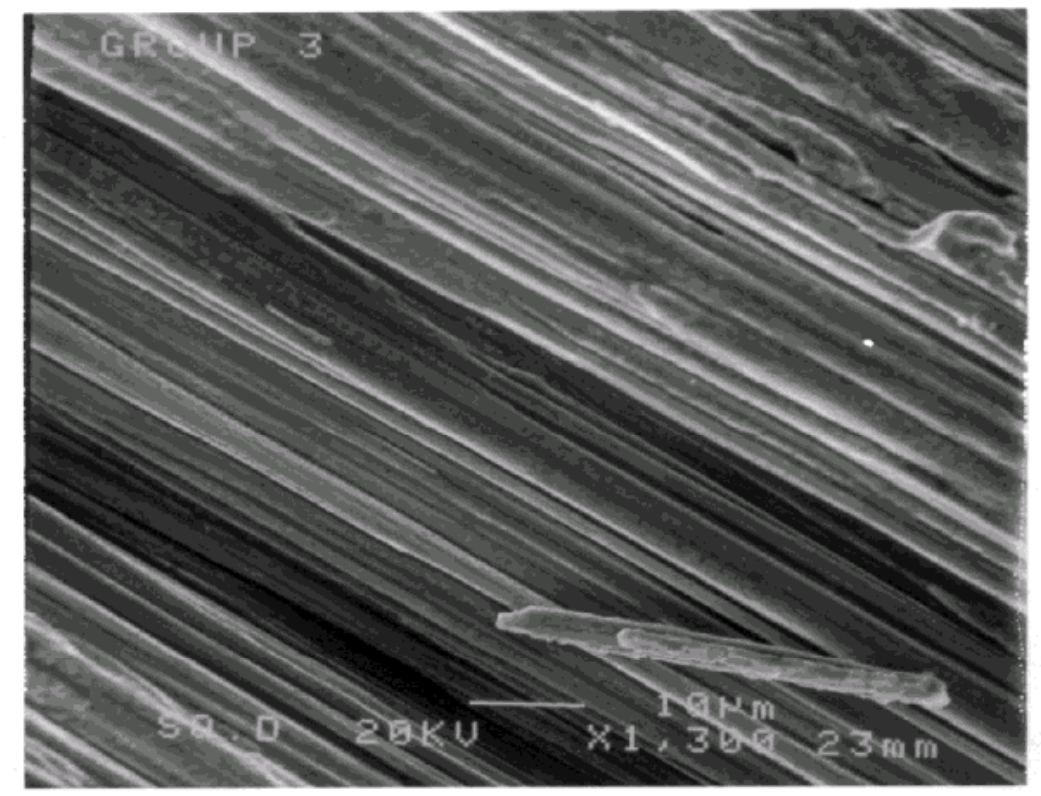

Fig. 9. Surface of silver whisker with metallic luster (\#5, Table 1), $\mathrm{x} 1,300$

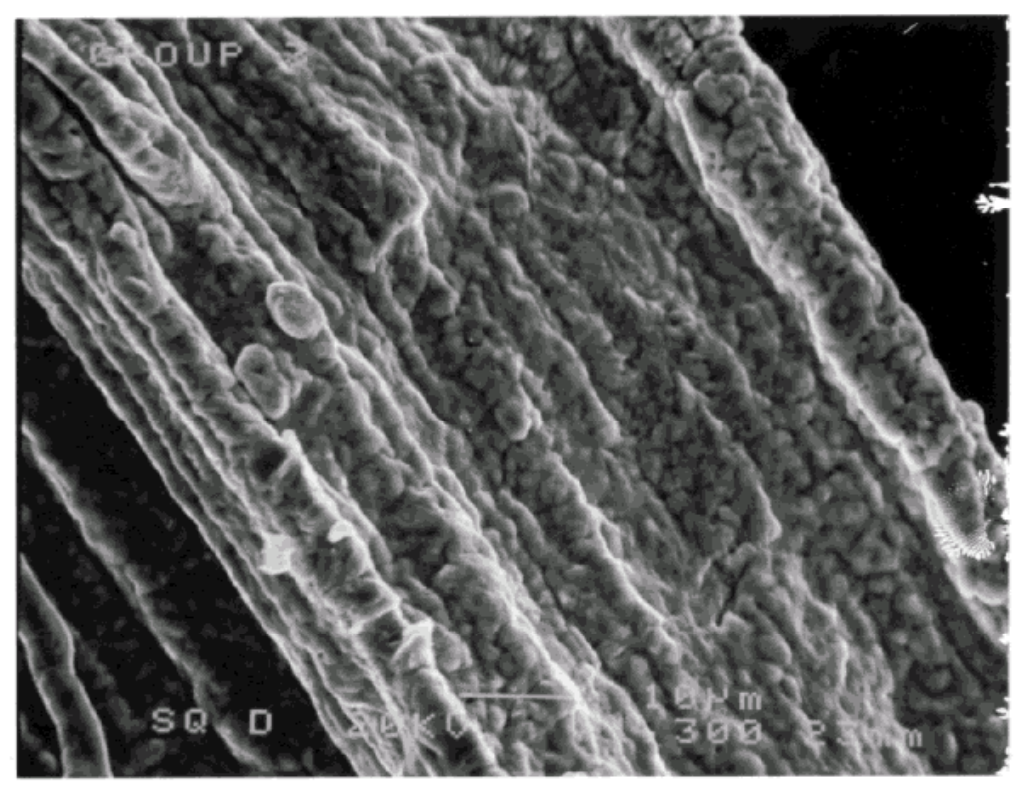

Fig. 10. Surface of the dark whisker (\#20, Table 1), x1,300 


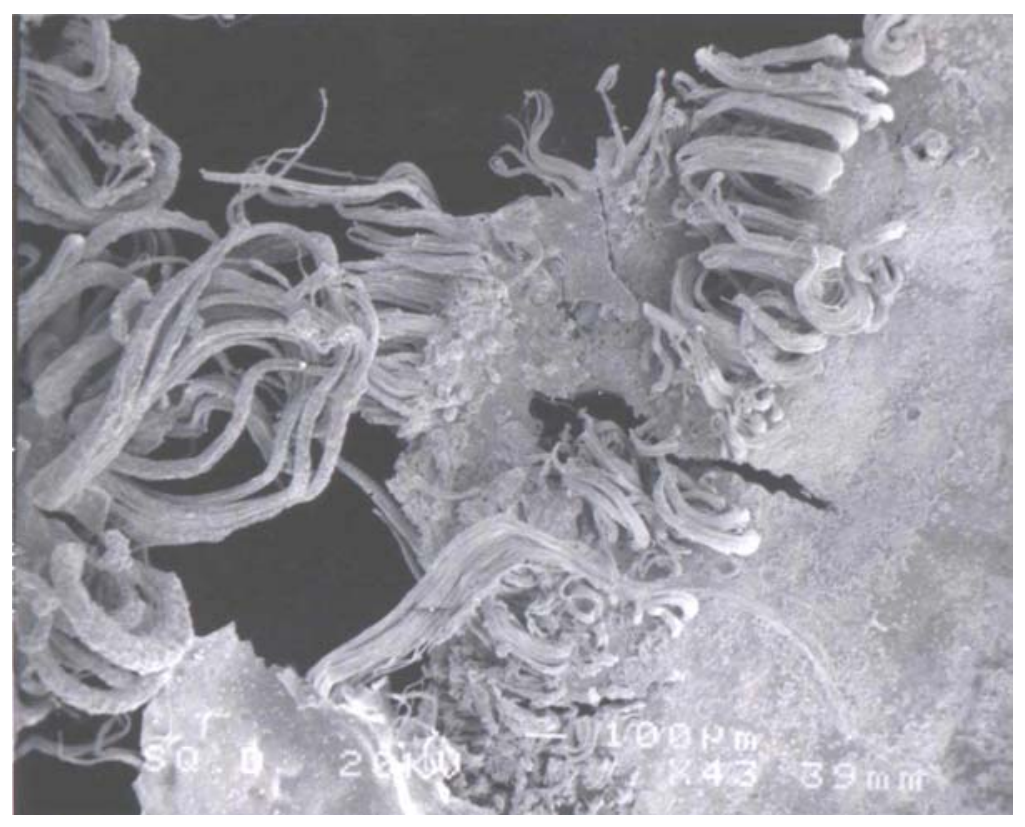

Fig. 11. Whiskers growing from the flakes, $\mathrm{x} 43$

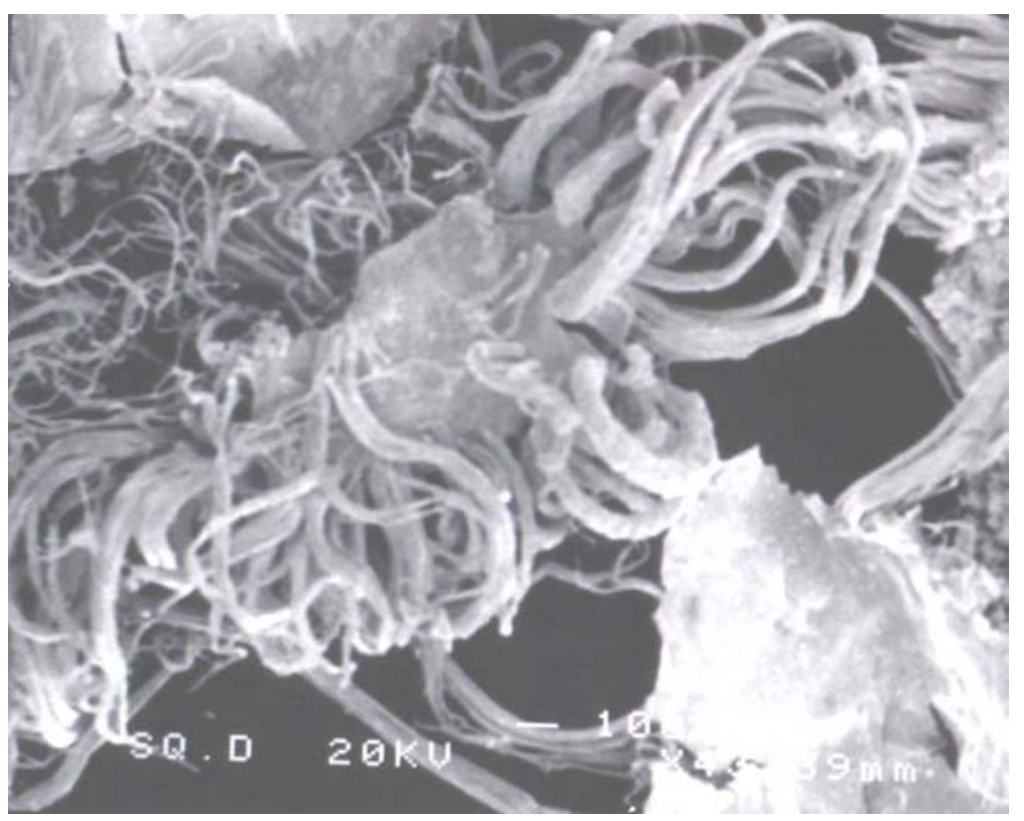

Fig. 12. Whiskers growing from the flakes, $x 43$ 


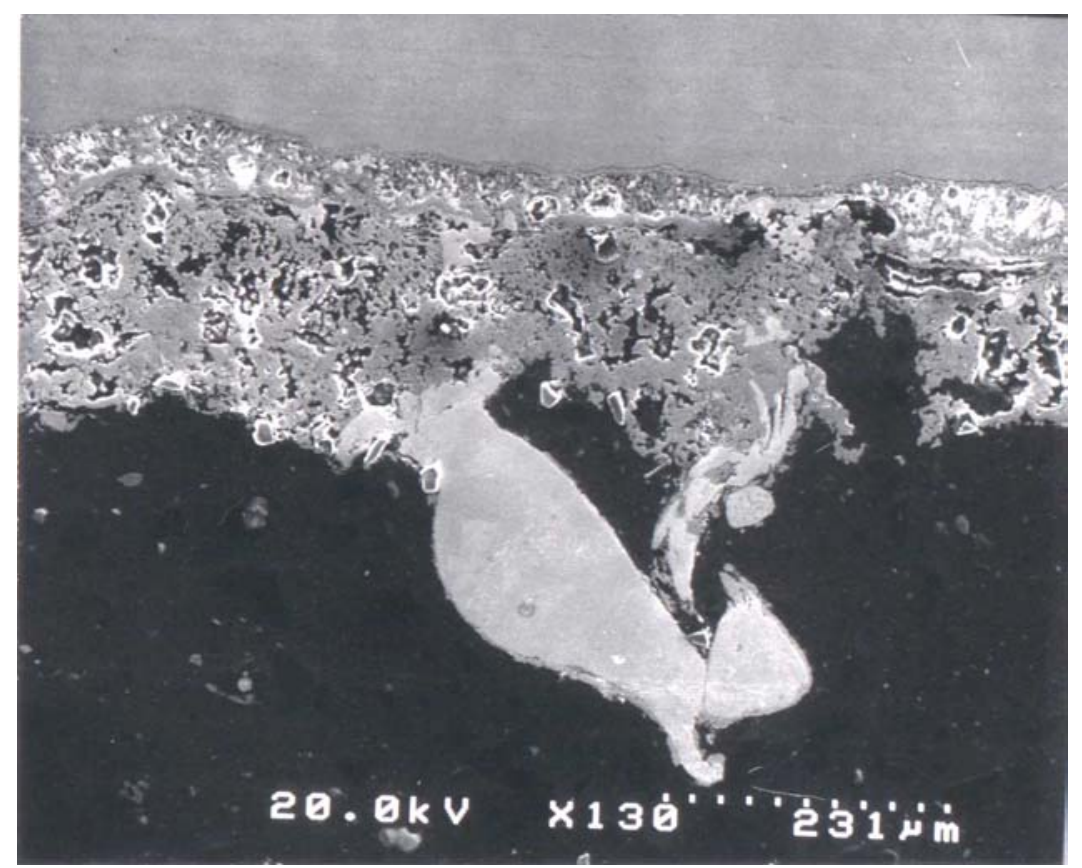

Fig. 13. Cross section of silver whisker growing from corrosion layer on copper part, x 130

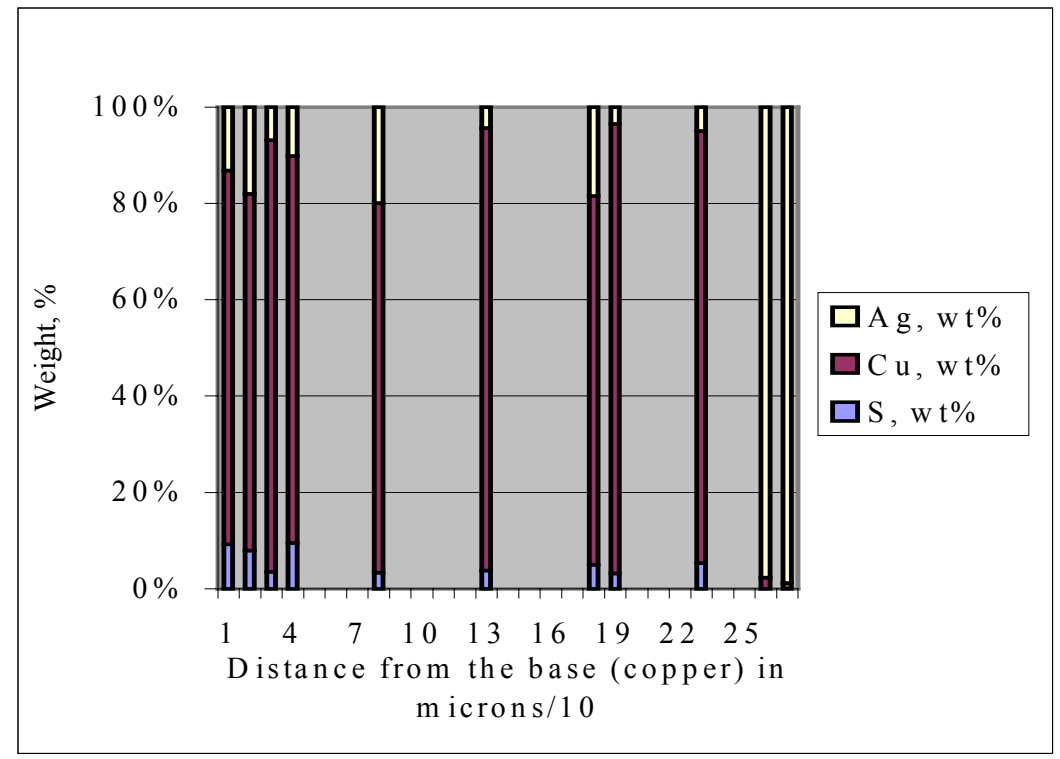

Fig. 14. Atomic profile of the sample with silver whisker growing from corrosion layer (Fig.13) 